\title{
Anatomical Description and Variations of the Anterior Arterial Brain Circulation in Colombian Cadaveric Specimens
}

\author{
Descripción Anatómica y Variaciones de la Circulación Cerebral \\ Arterial Anterior en Especímenes Cadavéricos Colombianos
}

\author{
Harold Palmera Pineda ${ }^{1}$; Luis Fernando Martínez²; Javier Amaya-Nieto ${ }^{3}$; \\ Andrés Camilo Prieto Forero ${ }^{4} \&$ Juan Carlos Luque Suarez ${ }^{5}$
}

\begin{abstract}
PALMERA, P. H.; MARTíneZ, L. F.; AMAYA-NIETO, J.; PRIETO, F. A. C. \& LUQUE, S. J. C. Anatomical description and variations of the anterior arterial brain circulation in Colombian cadaveric specimens. Int. J. Morphol., 39(6):1587-1591, 2021.

SUMMARY: Understanding microsurgical neuroanatomy is a fundamental part of the training of neurosurgeons. Notwithstanding the fact that throughout history the study in cadavers has been a fundamental part of training, the publication of these studies has never marked a trend, and in our country the available studies are limited. A descriptive anatomical study was carried out on 22 specimens regarding the anatomical arrangement of the anterior circulation arteries of the brain and the most frequent anatomical variants in the sample used. To this end, bilateral pterional and bifrontal approaches were performed, obtaining a total of 132 arteries, including supraclinoid internal carotid arteries (ICA), anterior cerebral arteries in their A1 segment (ACA), and middle cerebral arteries in their M1 segment (MCA). measurements in each of these segments were made and anatomical variants were documented. Out of 22 cadaveric specimens, $17(77 \%)$ were male. the mean age was 59 years (range 36-81 years). Internal carotid artery mean length was 12.73 and 12.86 in the right and left side respectively. Anatomical variants identified were hypoplasia of segment A1 in 1 (4.5\%) specimen, duplication in 1 (4.5\%) and trifurcation of segment M1 in $3(13.6 \%)$ specimens. A similarity was found between our data and data reported by literature, with some differences, especially in the anterior communicating artery.
\end{abstract}

KEY WORDS: Neuroanatomy,; Carotid artery; Anatomic models; Cadaveric simulation.

\section{INTRODUCTION}

Understanding the anatomy of the central nervous system is a fundamental part of neurosurgical training. The development of new techniques and the optimization of existing ones largely depend on the topographic study of cadaveric specimens (Shkarubo et al., 2018). Throughout history, multiple anatomical studies have been carried out in order to establish the most accurate anatomical parameters. This anatomical description in the studies addresses different topics, all aimed at the extensive knowledge of surface and deep anatomy, which permits the development and advancement of microsurgery techniques, by allowing a better approach to intracranial pathologies.

A study by doctors Leao et al. was published in 2017 (Reis et al., 2017), in which a spheno-pterional keyhole for performing pterional craniotomy was proposed. In this study,
200 approaches were carried out on 100 corpses and measurements to find this point were made. Following this same topic, we find ta study published by Kodera et al. (2017), in which they presented a modification to the orbigozygomatic craniotomy through cadaveric study in 11 specimens. We also found the proposals by Yag murlu et al. (2018), and Pescatori et al. (2017), who proposed cadaveric studies for approaching tumors of the pineal region and pathology of the IV cranial nerve, respectively.

These studies have allowed documenting important anatomical variations that have a significant surgical implication, such as the insular gyrus reported in a study carried out in Poland (Wysiadecki et al., 2018). Vascular neurosurgery has not been unaware of this trend, for which reason different anatomical studies have been performed,

\footnotetext{
${ }^{1}$ Neurosurgery Resident, Universidad Militar Nueva Granada - Hospital Militar Central, CLEMI researcher, Colombia.

${ }^{2}$ Neurosurgeon, Universidad Militar Nueva Granada, CLEMI researcher, Colombia.

${ }^{3}$ General Practitioner (GP), CLEMI researcher, Colombia.

${ }^{4}$ General Practitioner (GP), Universidad Militar Nueva Granada, MSc in Epidemiology, Universidad del Bosque, Colombia.

${ }^{5}$ Neurosurgeon, Hospital Militar Central, Professor of Neurosurgery at Universidad Militar Nueva Granada, CLEMI researcher, Colombia.
} 
such as the descriptive study carried out by Gunnal et al. (2019), in which they describe the posterior circulation in 170 specimens with their main patterns and variants. Similarly, functional studies have emerged, such as the one carried out in Australia, which sought to determine how vascular anatomy influenced flow dynamics (Burlakoti et al., 2017).

Again, the importance of these studies in surgical practice is highlighted, as demonstrated in the work carried out by Spiessberger et al. (2017), in which his minimally invasive technique for addressing the anterior communicating artery complex is described in four specimens. The project developed at the Barrow hospital was also found, where the hybrid extradural and intradural approach for performing the anterior clinoidectomy was studied in ten specimens (Meybodi et al., 2018). And finally, there are also contralateral approaches for the middle cerebral artery, in this case a study carried out on sixteen specimens by doctors Meybodi et al. (2019).

Considering the arguments previously presented, it is considered of utmost importance to determine the most common anatomical characteristics and anatomical variants of the arteries of the anterior cerebral circulation in cadaveric specimens from the Colombian population.

\section{MATERIAL AND METHOD}

Complying with local, national and international ethics regulations. Considering the risk of this research as the national law dictates, it was classified as a study without risk. A descriptive study was carried out on twenty-two cadaveric specimens within the facilities of the Latin American Center for Research and Training in Minimally Invasive Surgery (CLEMI), in the city of Sopo (Colombia). These specimens underwent bilateral pterional approaches

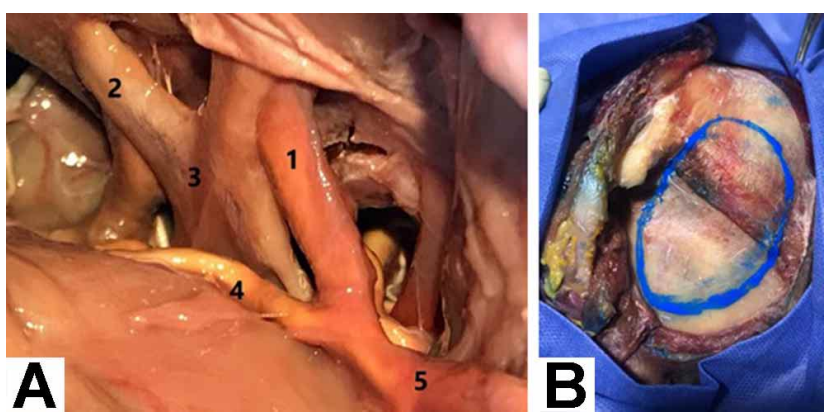

Fig. 1. A. View of the Opticocarotid relationships on the right side. B. Left Pterional Approach. (1) Internal Carotid Artery (ICA). (2) Optic nerve. (3) Optical chiasm. (4) Anterior Cerebral Artery (ACA). (5) Middle Cerebral Artery (MCA). and bifrontal approaches (Figs. 1 and 2), in order to dissect the arterial vascular structures. After this, lengths were in three segments were measured: Internal carotid artery (ICA), from the anterior clinoid to the bifurcation; Middle cerebral artery (MCA), from its origin to its first bifurcation; and Anterior cerebral artery (ACA), from its origin to the origin of the anterior communicating artery bilaterally (Fig. 3). Similarly, anatomical variants or pathological alterations were observed, which were described and documented (Figs. 4 and 5). The specimens were prepared by using the filling technique with jugular and carotid injection of colored synthetic ink.
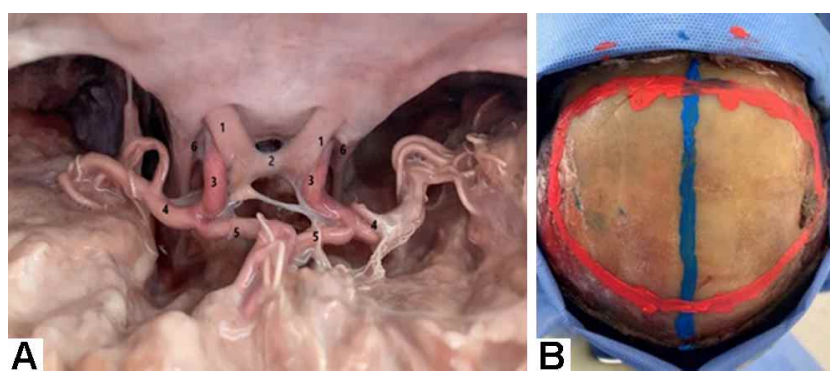

Fig. 2. A. Intradural view. Bifrontal approach. B. Bifrontal approach. A. (1) Optic nerve, (2) Optical chiasm, (3) Internal Carotid Artery (ICA), (4) Middle Cerebral Artery (MCA), (5) Anterior Cerebral Artery (ACA), (6) Anterior clinoid.

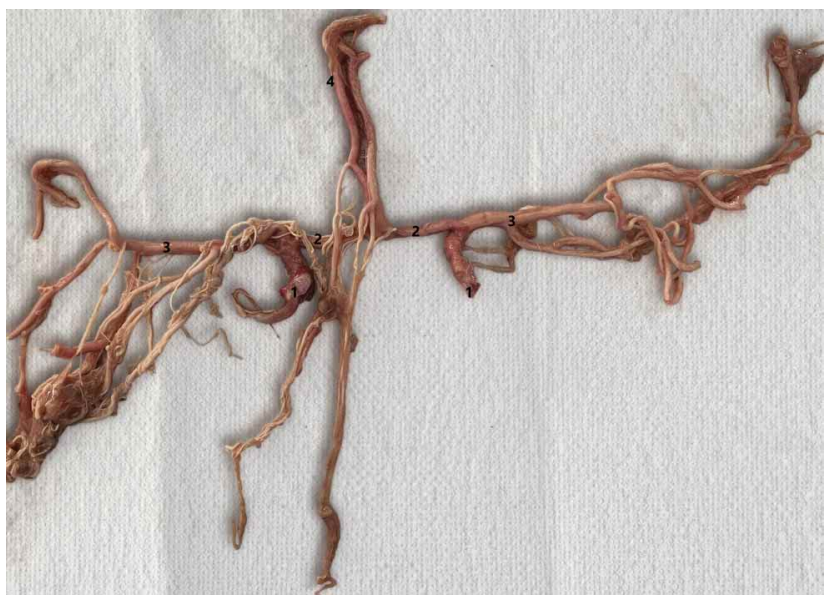

Fig. 3. Anterior view of Willis polygon. (1) Internal Carotid Artery (ICA), (2) Anterior Cerebral Artery (ACA), (3) Middle Cerebral Artery (MCA), (4) Postcommunicating Anterior Cerebral Artery (ACA).

Statistical analysis. Data for the statistical analysis were collected in an Excel 2013 database ensuring quality at the time of transcription, for subsequent statistical analysis using Rstudio software version 1.2.5033 (RStudio Team, 2015). The descriptive analysis was then performed with measures of central tendency, dispersion, and absolute frequencies according to the nature of the variable, with a confidence interval of $95 \%$, previously checking normality of the data using the Shapiro Wilk test. 


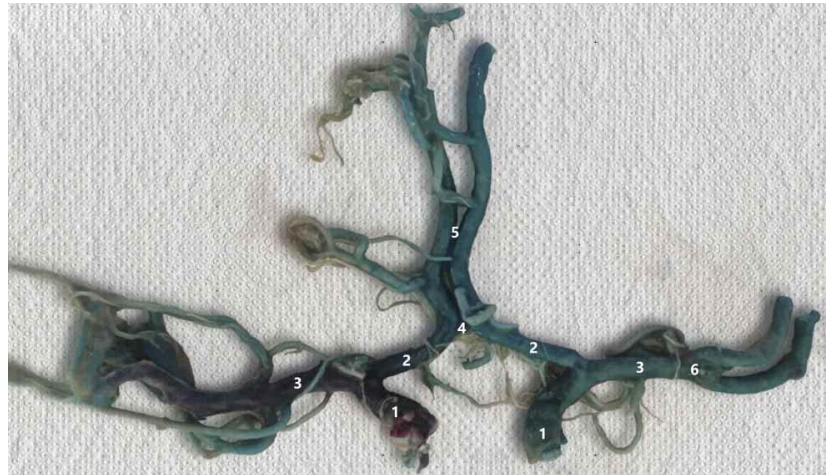

Fig. 4. Anterior polygon. (1) Internal Carotid Artery (ICA), (2) Anterior Cerebral Artery (ACA), (3) Middle Cerebral Artery (MCA), (4) Anterior Communicating Artery (AcoA), (5) Postcommunicating ACA, (6) Left MCA bifurcation.

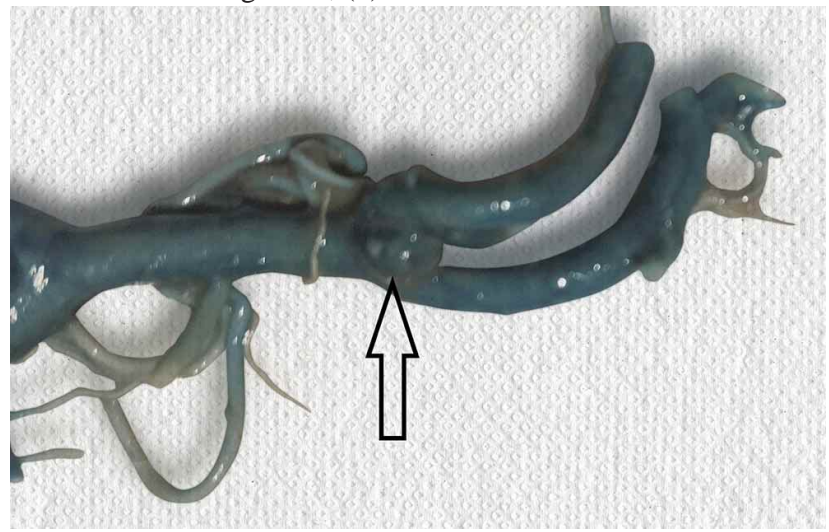

Fig. 5. Left Cerebral Middle Artery Aneurysm (MCA).

\section{RESULTS}

In total, 44 dissections corresponding to 22 specimens were performed, which were approached bilaterally, identifying and measuring the arterial structures in their ICA supraclinoid, MCA M1, and ACAA1 portions. The specimens were identified as male in $17(77 \%)$ and female in $5(23 \%)$, with a mean age of 59 years (range 3681 years). The identification of the superficial vein of the Silviano valley was carried out, identifying its most frequent anatomical distribution, which is shown in Table I. The arteries of the anterior polygon were measured bilaterally, obtaining the following average length for those on the right side: $12.73 \mathrm{~mm}$ for ICA, $14.91 \mathrm{~mm}$ for ACA, and 17.55 $\mathrm{mm}$ for MCA; and for the left side, $12.86 \mathrm{~mm}$ for ICA, $14.95 \mathrm{~mm}$ for ACA and $17.27 \mathrm{~mm}$ for MCA. As anatomical variants, on the left side were identified the following: hypoplasia of segment A1 in 1 specimen, duplication in 1 and trifurcation of segment M1 in 3 specimens; likewise, an aneurysm was identified in the M1 bifurcation (Fig. 3). On the right side, hypoplasia of A1 was found in 3 specimens, absence of M1 bifurcation continuing as a single trunk in 1, duplication in 1, and M1 trifurcation in 4. Table II reports the most relevant characteristics of the arteries studied.

Table I. Anatomical arrangement of the superficial Sylvian veins.

\begin{tabular}{lcc}
\hline Variable & Left side & Right side \\
\hline Absence & 4 & 1 \\
Single & 16 & 20 \\
Duplicate & 2 & 1 \\
\hline
\end{tabular}

\section{DISCUSSION}

The study of microsurgical anatomy has classically been carried out on cadaveric specimens, and the descriptions of what we know and accept as true have been obtained from these studies. However, population variability is a limitation since most of these studies have been carried out on European or North American populations (Pescatori et al.; Wysiadecki et al.). In our study, we found that most of the specimens corresponded to older adult men, there was no significant difference in the lengths of the segments measured between both sides, and the presence of anatomical variants was greater on the right side, although the pathological finding of the aneurysm was documented on the left side in one male. Compared to Dr. Rhoton's book, the quintessential textbook, in terms of anatomical variants such as the arrangement of M1, we

Table II. Arteries of the anterior polygon.

\begin{tabular}{lllll}
\hline Variable & $\begin{array}{l}\text { Average } \\
\text { length }(\mathrm{mm})\end{array}$ & $\begin{array}{l}\text { Range } \\
(\mathrm{mm})\end{array}$ & $\begin{array}{l}\text { Standard } \\
\text { deviation }\end{array}$ & Anatomical variant \\
\hline Left ICA & 12.86 & $8-15$ & 2.83 & No \\
Right ICA & 12.73 & $9-21$ & 2.73 & No \\
Left ACA & 14.95 & $10-20$ & 2.45 & Hypoplasia $4.5 \%$ \\
Right ACA & 14.91 & $10-21$ & 2.92 & Hypoplasia $13.6 \%$ \\
Left MCA & 17.27 & $10-24$ & 4.07 & Duplicate $4.5 \%$, Trifurcation $13.6 \%$, Aneurism $4.5 \%$ \\
Right MCA & 17.55 & $9-35$ & 5.6 & Bifurcation absence $4.5 \%$, Duplicate $4.5 \%$, Trifurcation $18.2 \%$ \\
\hline
\end{tabular}

Internal carotid artery (ICA), anterior cerebral artery ACA, middle cerebral artery. (MCA). 
found that they report bifurcation in $78 \%$, and trifurcation in $12 \%$, while our study shows $75 \%$ and $15 \%$ respectively; likewise, for example regarding the lengths found by Dr Rothon, in the case of A1 it was $12.7 \mathrm{~mm}$ on average, while in our study it was $14.9 \mathrm{~mm}$, slightly longer, and the presence of two anterior communicating arteries in their study was $30 \%$, while in our study it was only $9 \%$. Within the limitations of our study, we can mention the heterogeneous distribution in terms of sex, and the sample size (Rhoton Jr., 2002).

Although an anatomical description was sought in our population, there was a heterogeneous distribution in terms of gender, with male prevailing. However, the age group was adjusted to the epidemiology reported for the presence of aneurysmal disease, and an example of this is that we found an aneurysm in our study. Carrying out this type of study should be massified and replicated in neurosurgery faculties, in order to strengthen knowledge in microsurgical neuroanatomy and share these experiences with the scientific community.

\section{CONCLUSIONS}

Despite the limitations described, the study provides more detailed knowledge of the vascular microsurgical anatomy of the arteries of the anterior polygon in the Colombian population, showing anatomical similarities with what has been reported in the international literature, and differences in anatomical variants. This should be understood as an effort to generate essential knowledge for the approach to vascular pathology in our environment, and to motivate the development of more studies aimed at deepening our knowledge in microsurgical neuroanatomy.

PALMERA, P. H.; MARTÍNEZ, L. F.; AMAYA-NIETO, J.; PRIETO, F. A. C. \& LUQUE, S. J. C. Descripción anatómica y variaciones de la circulación cerebral arterial anterior en especímenes cadavéricos colombianos. Int. J. Morphol., 39(6):1587-1591, 2021.

RESUMEN: Entender la neuroanatomía microquirúrgica es una parte fundamental de la formación de los neurocirujanos. A pesar de que, durante la historia, el estudio en cadáveres ha sido parte fundamental del entrenamiento, no ha sido tendencia la publicación de estos estudios, y en nuestro país son limitados los que se encuentran. Se realizó un estudio descriptivo anatómico en 22 especímenes acerca de la disposición anatómica de las arterias de la circulación cerebral anterior y las variantes anatómicas más frecuentes en población colombiana. Para dicho objetivo se realizaron abordajes bilaterales pterionales, y bifrontales obteniendo un total de 132 arterias incluyendo las arterias carotídeas internas supraclinoideas (ACI), arterias cerebrales anteriores en su segmento A1 (ACA) y las arterias cerebrales medias en su segmento M1 (ACM), se realizaron mediciones en cada uno de estos segmentos y se documentaron las variantes anatómicas. De los 22 especímenes cadavéricos, 17 (77\%) eran masculinos, la edad media fue de 59 años (rango 36-81 años). La longitud media de la arteria carótida interna fue de $12,73 \mathrm{~mm}$ en el lado derecho y de 12,86 mm en el lado izquierdo. Las variantes anatómicas identificadas fueron hipoplasia del segmento A1 en $1(4,5 \%)$, duplicación de A1 en $1(4,5 \%)$ y trifurcación del segmento M1 en $3(13,6 \%)$ muestras. Se encontró una similitud entre nuestros datos y los reportados por la literatura, con algunas diferencias, especialmente en el segmento de la arteria comunicante anterior.

PALABRAS CLAVE: Neuroanatomía; Arteria carótida; Modelos anatómicos; Simulación cadavérica.

\section{REFERENCES}

Burlakoti, A.; Kumaratilake, J.; Taylor, J.; Massy-Westropp, N. \& Henneberg, M. The cerebral basal arterial network: morphometry of inflow and outflow components. J. Anat., 230(6):833-41, 2017.

Gunnal, S. A.; Farooqui, M. S. \& Wabale, R. N. Study of middle cerebral artery in human cadaveric brain. Ann. Indian Acad. Neurol., 22(2):18794, 2019.

Kodera, T.; Arishima, H.; Yamada, S.; Arai, H.; Akazawa, A.; Higashino, Y.; Kitai, R.ç, Iino, S.; Bertalanffy, H. \& Kikuta, K. I. Orbitozygomatic craniotomy with modified Zabramski's technique: a technical note and anatomic and clinical findings. World Neurosurg., 97:49-57, 2017.

Meybodi, A. T.; Lawton, M. T.; Rubio, R. R.; Yousef, S. \& Benet, A. Contralateral approach to middle cerebral artery aneurysms: an anatomical-clinical analysis to improve patient selection. World Neurosurg., 109:e274-e280, 2018.

Meybodi, A. T.; Lawton, M. T.; Yousef, S.; Guo, X.; Sánchez, J. J. G.; Tabani, H.; García, S.; Burkhardt, J. K. \& Benet, A. Anterior clinoidectomy using an extradural and intradural 2-step hybrid technique. J. Neurosurg., 130(1):238-47, 2019.

Pescatori, L.; Niutta, M.; Tropeano, M. P.; Santoro, G. \& Santoro, A. Fourth cranial nerve: surgical anatomy in the subtemporal transtentorial approach and in the pretemporal combined inter-intradural approach through the fronto-temporo-orbito-zygomatic craniotomy. A cadaveric study. Neurosurg. Rev., 40(1):143-53, 2017.

Reis, B. L.; Da Silveira, R. L. \& Gusmão, S. N. S. Sphenopterional point: strategic point for burr role placement in frontotemporal craniotomies. World Neurosurg., 105:399-405, 2017.

Rhoton Jr., A. L. The supratentorial arteries. Neurosurgery, 51(4 Suppl.):S53-120, 2002.

RStudio Team. RStudio: Integrated Development Environment for $R$ (1.2.5033). Orange Blossom, 2015.

Shkarubo, M. A.; Shkarubo, A. N.; Dobrovolsky, G. F.; Polev, G. A.; Chernov, I. V.; Andreev, D. N.; Karnaukhov, V. V. \& Koval, K. V. Making anatomic preparations of the human brain using colored silicone for vascular perfusion staining (technical description). World Neurosurgery, 112:110-6, 2018.

Spiessberger, A.; Baumann, F.; Nevzati, E.; Kothbauer, K. F.; Fandino, J. \& Muroi, C. Minimally invasive medial supraorbital, combined subfrontal-interhemispheric approach to the anterior communicating artery complex-a cadaveric study. Acta Neurochir. (Wien), 159(6):1079$85,2017$. 
PALMERA, P. H.; MARTínEZ, L. F.; AMAYA-NIETO, J.; PRIETO, F. A. C. \& LUQUE, S. J. C. Anatomical description and variations of the anterior arterial brain circulation in Colombian cadaveric specimens. Int. J. Morphol., 39(6):1587-1591, 2021.

Wysiadecki, G.; Makiewicz, A.; Roz niecki, J.; Polguj, M.; Haadaj, R.; Z ytkowski, A. \& Topol, M. Anatomical variations of the insular gyri: A morphological study and proposal of unified classification. Clin. Anat., 31(3):347-56, 2018.

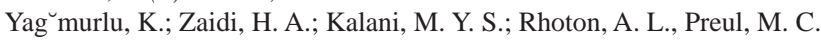
\& Spetzler, R. F. Anterior interhemispheric transsplenial approach to pineal region tumors: Anatomical study and illustrative case. $J$. Neurosurg., 128(1):182-92, 2018.
Corresponding author:

Harold Palmera Pineda, M.D

Neurosurgery department

Universidad Militar Nueva Granada

Hospital Militar Central

Cl. 134 \#7b-83

Bogotá

COLOMBIA

E-mail: har9hol@gmail.com

Received: 18-05-2021

Accepted: 01-09-2021 